\title{
Microwave ablation in the treatment of liver tumors. A better tool or simply more power?
}

\author{
Zeno Sparchez ${ }^{1,2}$, Tudor Mocan ${ }^{1,2}$, Pompilia Radu ${ }^{3}$, Iuliana Nenu ${ }^{1,2}$, Mihai Comsa ${ }^{2}$, Nadim \\ Al Hajjar ${ }^{2,4}$, Emil Mois ${ }^{2,4}$, Adrian Bartos ${ }^{2,4}$, Gabriel Kacso ${ }^{5}$, Mihaela Sparchez ${ }^{6}$
}

${ }^{1} 3^{\text {rd }}$ Medical Department, "Iuliu Hatieganu" University of Medicine and Pharmacy, Cluj-Napoca, Romania, ${ }^{2}$ Institute for Gastroenterology and Hepatology, Cluj-Napoca, Romania, ${ }^{3}$ Hepatology, Department of Clinical Research, University of Bern, Bern, Switzerland; University Clinic for Visceral Surgery and Medicine, Inselspital Bern, Bern, Switzerland, ${ }^{4} 3^{\text {rd }}$ Surgical Department, "Iuliu Hatieganu" University of Medicine and Pharmacy Cluj-Napoca, Romania, ${ }^{5}$ Oncological Department, "Iuliu Hatieganu" University of Medicine and Pharmacy Cluj-Napoca, Romania, ${ }^{6}$ Paediatric Department, "Iuliu Hatieganu" University of Medicine and Pharmacy Cluj-Napoca, Romania

\begin{abstract}
It has been a long time since tumor ablation was first tested in patients with liver cancer, especially hepatocellular carcinoma. Since than it has become a first line treatment modality for hepatocellular carcinoma. Over the years, the indications of thermal ablation have expanded to colorectal cancer liver metastases and intrahepatic cholangiocarcinoma as well. Together with the new indication for ablation, new ablation devices have been developed as well. Among them microwave ablation shows potential in replacing radiofrequency ablation as the preferred method of thermal ablation in liver cancer. The debate whether radiofrequency or microwave ablation should be the preferred method of treatment in patients with liver cancer remains open. The main purpose of this review is to offer some answers to the question: Microwave ablation in liver tumors: a better tool or simply more power? Various clinical scenarios will be analyzed including small, medium, and intermediate size hepatocellular carcinoma, colorectal cancer liver metastases and intrahepatic cholangiocarcinoma. Furthermore, the advantages, limitations, and technical considerations of MWA treatment will be provided also.

Keywords: microwave ablation; hepatocellular carcinoma; intrahepatic cholangiocarcinoma; colorectal cancer liver metastases
\end{abstract}

\section{Introduction}

Tumor ablation is a minimally invasive technique that is commonly used in the treatment of many tumors including primary and secondary liver neoplasm. In secondary liver neoplasm, ablation techniques are an important option for patients who are not surgical candidates [1], while in patients with small hepatocellular carcinoma (HCC) ablation is considered a potential first-line treatment [2]. In the last two decades, percutaneous treat-

Received 14.04.2020 Accepted 30.05.2020

Med Ultrason

2020, Vol. 22, No 4, 451-460

Corresponding author: Dr. Tudor Mocan

Institute for Gastroenterology and Hepatology, 19-21Croitorilor street, Cluj-Napoca, Romania, E-mail: mocan_tudor@yahoo.com Phone: +40799861946 ments for malignant liver tumors have been substantially improved. The most widely used method of those available has been monopolar radiofrequency ablation (RFA), although in the last 5 years microwave ablation (MWA) has gained acceptance as a favorable alternative and in some cases a preferred choice of ablation modality [3]. All the great improvements of the MWA generators, needles, guidance softs during the last years have allowed for the current indications of tumor ablation to expand to intrahepatic cholangiocarcinoma (iCCA) as well [4]. We already have some reports, although preliminary, for the use of MWA in the treatment of iCCA [5]. This paper reviews the evidence supporting the use of MWA in the treatment of liver cancer. The clinical application of MWA in various clinical scenarios will be discussed. Among clinical scenarios we include small, medium, and intermediate size HCC, colorectal cancer liver metasta- 
ses (CRCLM) and iCCA. Furthermore, the advantages, limitations, and technical considerations of MWA treatment will be also provided.

\section{Mechanism of tissue heating}

The goal of thermal ablation is to heat target tissues to temperatures that can induce immediate coagulative necrosis (typically over $60{ }^{\circ} \mathrm{C}$ ). A complete treatment should cover the tumor plus a $5-10 \mathrm{~mm}$ safety margin (analogous to a surgical margin) while sparing healthy parenchyma and vulnerable non-target structures $[3,6-$ 9]. In MW ablation, the mechanism of heat generation is based on rapid frictional movement of water molecules in the high frequency $(900-2500 \mathrm{MHz})$ electromagnetic field.

Unlike RFA, microwaves are capable of effectively heating and propagating through many types of tissue, even those with low electrical conductivity, high impedance, or low thermal conductivity. All MWA systems are composed of three basic elements: microwave generator, low-loss flexible coaxial cable and microwave antenna. The diameter of the antenna used commonly in clinics is 2 to $2.8 \mathrm{~mm}(14-16 \mathrm{G})$.

To prevent over-heating of the shaft, avoiding skin injury and permitting further deposition of energy into tissue with low impedance during ablation, cooled-shaft antennae have been developed [6,10]. Multiple antennae (2-4) can also be used to create larger, more conformal and confluent ablation zones [11]. Simultaneous multiantenna MWA of liver tumors results in large (ablation volume nearly threefold larger with 3 antennas than that achieved with 2 antennas), nearly spherical ablation zones [11].

There are 3 generations of microwave systems, the 3 rd one with incorporating antenna cooling systems and high-power generators [12]. Conventional MWA systems use either 915 or $2450 \mathrm{MHz}$ frequency. As with other heat-based thermal ablation devices the ablation zone size and shape is less predictable being influenced by physical parameters of the liver parenchyma such as thermal conductivity and perfusion rate [12]. The newer generation MWA systems with internal cooling attempt to overcome the limitations of conventional systems and to provide predictable ablation areas not impacted by tissue type or target location [12]. A large, precise, and spherical ablation zone is achieved using three different kinds of control: field, thermal and wavelength $[12,13]$.

\section{Major advantages of MWA over RFA}

MW ablation has several advantages, including greater and more uniform penetration of energy into tissue (resulting in a larger area of ablation), higher intratumoral temperatures $(>150 \mathrm{C})$, and faster ablation times $[3,8,9,14,15]$.MWA is less susceptible to the heat-sink effect and thus it could be used to treat tumors in close contact to large vessels $[3,6,9]$. However, it should be kept in mind that by producing larger zones of necrosis, MWA increases the risk of potential complications owing to collateral injury to adjacent nontarget organs [10].

\section{Technique}

There are different ways to perform MWA (percutaneous, laparoscopic or intraoperative); however, the percutaneous approach offers several advantages [3,16-18]. It is the least invasive, relatively expensive, can be performed on an outpatient basis and can be repeated to treat recurrent tumors [16]. In clinical practice all patients should undergo ultrasound (US), contrast enhanced US (CEUS) and contrast enhanced computed tomography (CT) or gadolinium-enhanced magnetic resonance imaging (MRI) in order to delineate the target tumor(s) before MWA. MWA has been performed by using US, CT, or MRI guidance $[15,19,20]$. Compared to CT or MRI guidance, US has real time features and allows scanning the body from different positions and angles, and hence US is more convenient. In cases with difficulties in targeting the lesions or lesions not detectable at US, CEUS and/ or fusion imaging techniques (US-CT, US MRI) may be used [21-24]. Patients should fast for at least 6 hours before ablation. Percutaneous MWA is usually performed under local anesthesia and analgosedation. After the procedure the patients should be monitored at least 6 hours. A one-night hospital stay is preferable and mostly practiced although outpatient procedures have been also reported $[3,9,15]$. As with RF ablation, MW ablation involves placement of a needle electrode directly into the target tumor, typically under US guidance (fig $1 \mathrm{a}, \mathrm{b}$ ). During the procedure, the ablation zone appears on US as hyperechoic spots around the antenna, thus confirming that the heat was applied. The hyperechogenic area is caused by microbubbles and gas released from the heated tissue and does not correlate with adverse tissue coagulation [3].

In order to destroy possible micro-metastases or microscopic foci around the tumor so preventing local tumor progression, ablation with a margin of $5-10 \mathrm{~mm}$ around the tumor has been recommended $[3,25]$. In many cases, multiple overlapping ablations may be required to create the necessary ablation zone size. Overlapping ablations can be created in 2 ways: 1) multiple insertions of a single antenna to create overlapping ablation zones in a sequential manner or 2) multiple antennas ablating simultaneously to create a confluent ablation zone. Sequential antenna applications performed by repositioning a single antenna can be technically challenging as gas bubbles 


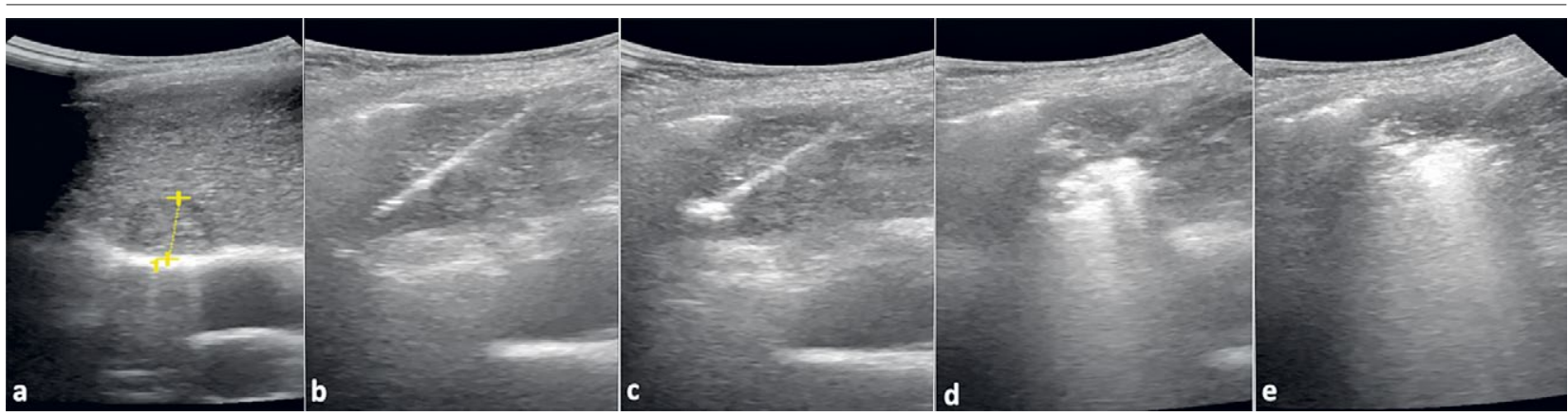

Fig 1. a) MWA of a 1,8 cm hepatocellular carcinoma nodule. b) the electrode is placed into the lesion (>).; c-e) an echogenic spot is increasing around the antenna tip, covering the lesion

and tissue contraction decrease the visibility of the target area [6]. The size of the ablation zone can be roughly assessed by the expanding hyperechoic area during ablation. The ablation is considered ended when the transient hyperechoic zone around the antennae on grey-scale US merges and covers the target region (fig 1c-e) [15].

For accurate assessment of the treatment efficacy, 1-3 thermocouples can be placed percutaneously at different sites $5-10 \mathrm{~mm}$ outside the tumor and connected to a thermal monitoring system attached to the MW generator. The ablation is considered to be completed if the measured temperature is $60^{\circ} \mathrm{C}$ by the end of treatment and remain at $54^{\circ} \mathrm{C}$ for at least $3 \mathrm{~min}$ [15]. By the same system overheating can also be avoided, thus decreasing the incidence of complications [15].

The procedure should be also stopped immediately in cases of the appearance of major complications including massive bleeding, severe pain, severe pneumothorax or perforation of adjacent organs [3]. In order to ensure complete avascularity of the tumor, to delineate precisely the ablation area and its relation to the tumor or to provide guidance for retreatment of suspected non-ablated parts of the lesion, CEUS can be performed at the end of the procedure $[26,27]$. The resulting ablation area after 1 session tends to be much more elliptical with the conventional MWA systems and more spherical with the newer one (fig 2) [3]. With some devices 1-3 hallmarks of the antennas are seen within the lesion. If any residual tumor is found, additional ablations should be performed [26] (fig 3). Using CEUS at the end of ablation, the residual tumor rate was decreased from 16.7 to $0 \%$ [26]. In recent years, many centers have introduced CEUS for the immediate assessment of treatment efficacy.

There are some challenges in the CEUS evaluation of the ablated zone. To avoid the hyperechoic cloud which may mask untreated areas, CEUS is usually performed 10-15 min after MWA $[26,28]$. Perilesional hyperemia is

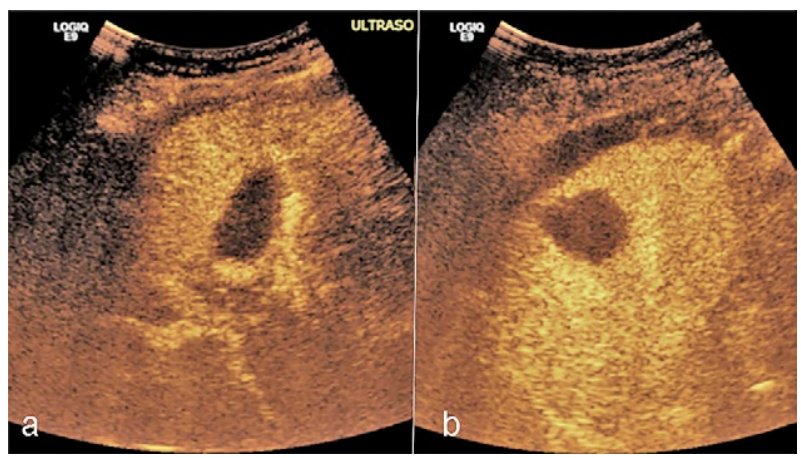

Fig 2. a) The shape of ablated zone tends to be more elliptical. CEUS image; b) an almost round ablated zone is obtained with $3^{\text {rd }}$ generation systems

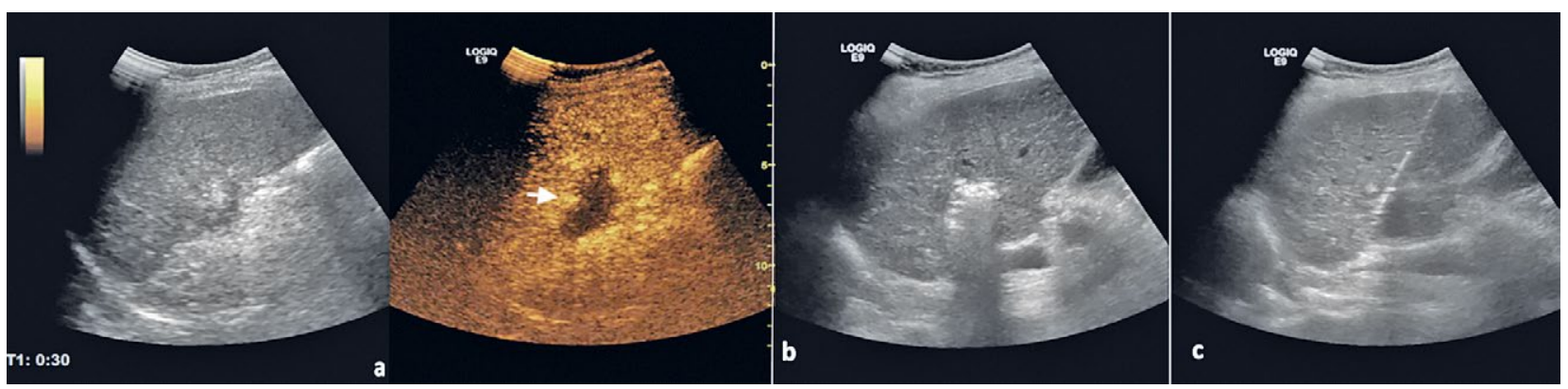

Fig 3. a) Untreated tumor zone in MWA procedure-split mode image; b) Additional insertion is performed in the enhanced area; c) ablation of that area is performed. Note the echogenic cloud covering that part of the tumor 
frequently present immediately after ablation and may be mistaken as a residual tumor. Unlike a residual tumor, peri- ablation hyperemia demonstrates a uniform rim of hyperenhancement in the arterial phase which persists throughout all phases $[26,28]$. Pseudo-enhancement corresponds to the most echogenic region of the ablation zone on gray scale US and tends to appear during the portal venous phase, in a region which was avascular during the arterial phase [26]. Maybe the most challenging issue is to delineate correctly the ablation area and its relationship to the tumor and to detect a possible enhancing area in a 3D fashion [26]. The above issues are even more critical for metastasis ablation [26,29]. This technical limitation of CEUS may be responsible for some recurrence even in cases with postprocedural CEUS evaluation $[26,28]$. The evaluation may be substantially improved by using fusion techniques such as CEUS-CT or CEUS-MRI fusion imaging [24].

CEUS, CT or MRI can also be used for the evaluation of tumor response during follow-up. Currently CT remains the procedure of choice for the follow-up of patients who do not have a contraindication to iodinated intravenous contrast material $[3,11,30]$. CT images obtained 4-6 weeks after therapy demonstrate successful treatment as a non-enhancing area with or without a peripheral enhancing rim. In the follow-up protocol routine CEUS and contrast CT is repeated at 1 and 3 months after MWA and then at longer intervals over the course of time (4-6 months), depending on imaging findings, underlying tumor and patient risk factors [3,27].

The complications of MW ablation are similar to those reported after RF ablation. Bleeding is the most frequent complication of MWA but it rarely requires trans-

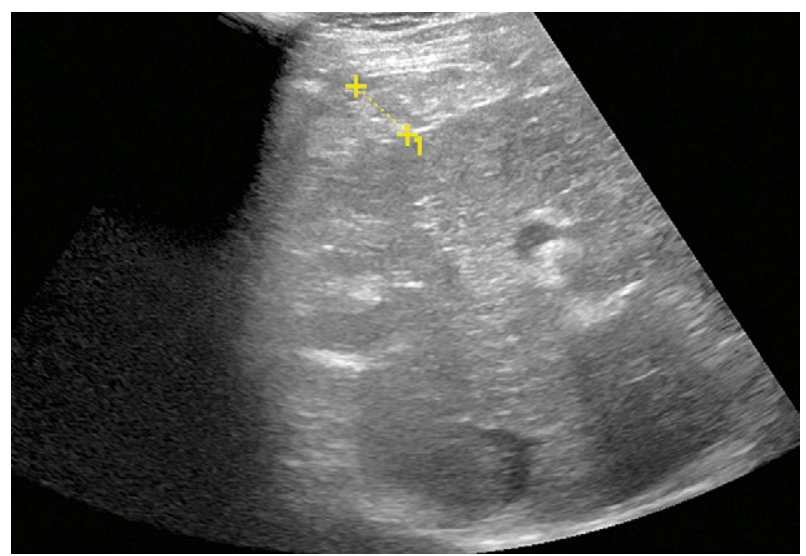

Fig 4. Perihepatic bleeding after MWA. An echogenic material is seen during ablation close to the liver capsule $(<)$

fusion ( $<1 \%$ ) (fig 4) [3]. In 3 systematic reviews, minor, major complication and mortality rates for MWA were $7.3-12.9 \%, 2.9-4.6 \%$ and $0-0.23 \%$, respectively [31-33]. Use of noncooled-shaft antenna and an increased number of MW ablation sessions were associated with a higher rate of major complications in a large cohort of 1136 patients treated by MWA [32]. There are no significant differences in mortality rates $(0.15 \%$ vs. $0.25 \%)$ between RFA and MWA in liver tumors [31].

\section{MWA in colorectal cancer liver metastases}

Colorectal cancer (CRC) is a malignancy with high incidence and $20-50 \%$ of patients have liver metastases (CRCLM), either detected at diagnosis of primary tumors (synchronous) or at a later stage (metachronous) [34]. The main method used to treat CRCLM is surgical resection. Unfortunately, only $10-20 \%$ patients are suitable for this procedure [35]. In this setting, ablation tech-

Table I. Studies comparing MWA with RFA in patients with liver metastasis

\begin{tabular}{|c|c|c|c|c|c|c|c|}
\hline Author & Design & $\begin{array}{l}\text { No of } \\
\text { patients }\end{array}$ & $\begin{array}{l}\text { Complete } \\
\text { ablation rate }\end{array}$ & $\begin{array}{l}\text { Local tumor } \\
\text { progression }\end{array}$ & $\begin{array}{l}\text { Mean } \\
\text { ablation time }\end{array}$ & $\begin{array}{l}\text { Overall } \\
\text { survival }\end{array}$ & Complications \\
\hline $\begin{array}{l}\text { Sparchez } \\
{[40]}\end{array}$ & $\begin{array}{l}\text { Retro- } \\
\text { spective }\end{array}$ & 61 & $\begin{array}{l}100 \% \text { vs. } 71.35 \%, \\
p=0.008, \\
\text { in favor of MWA }\end{array}$ & $\begin{array}{l}\text { No difference, } \\
p=0.154\end{array}$ & $\begin{array}{l}10 \text { minutes for MWA } \\
\text { vs. } \\
14 \text { minutes for RFA, } \\
p=0.003\end{array}$ & $\begin{array}{l}\text { No difference } \\
\mathrm{p}>0.05\end{array}$ & $\begin{array}{l}\text { No difference, } \\
p=0.46\end{array}$ \\
\hline $\begin{array}{l}\text { Correa-Galego } \\
{[38]}\end{array}$ & $\begin{array}{l}\text { Retro- } \\
\text { spective }\end{array}$ & 134 & Not reported & $\begin{array}{l}\text { At } 2 \text { years } \\
7 \% \text { vs. } 18 \% \\
\text { in favor of MWA; } \\
p=0.01\end{array}$ & Not reported & $\begin{array}{l}\text { No difference, } \\
p=0.5\end{array}$ & $\begin{array}{l}\text { No difference, } \\
\mathrm{p}=0.8\end{array}$ \\
\hline $\begin{array}{l}\text { Shady W } \\
\text { [39] }\end{array}$ & $\begin{array}{l}\text { Retro- } \\
\text { spective }\end{array}$ & 110 & $\begin{array}{l}97 \% \text { for MWA } \\
\text { and } 93 \% \text { for RFA, } \\
p=0.47\end{array}$ & $\begin{array}{l}\text { No difference, } \\
p=0.84\end{array}$ & $\begin{array}{l}7 \text { minutes for MWA } \\
\text { vs. } \\
10 \text { minutes for RFA, } \\
p=<0.001\end{array}$ & Not reported & $\begin{array}{l}\text { No difference, } \\
p=0.35\end{array}$ \\
\hline $\begin{array}{l}\text { Martin } \\
{[37]}\end{array}$ & $\begin{array}{l}\text { Pro- } \\
\text { spective }\end{array}$ & 80 & $\begin{array}{l}98 \% \text { for MWA } \\
\text { and } 92 \% \text { for RFA }\end{array}$ & $\begin{array}{l}2 \% \text { for MWA vs. } \\
17 \% \text { for RFA }\end{array}$ & $\begin{array}{l}13 \text { minutes for MWA } \\
\text { vs. } \\
40 \text { minutes for RFA }\end{array}$ & Not reported & Not reported \\
\hline
\end{tabular}

$\mathrm{MWA}=$ microwave ablation; RFA $=$ radiofrequency ablation; No $=$ number; $\mathrm{p}=$ level of significance; vs. $=$ versus 
niques are widely used. Although the available studies of MWA on colorectal liver metastasis are fewer than those of RFA, the indications, contraindications and patient selection criteria for this procedure are similar to those of RF ablation [36]. The first study comparing MWA with RFA was published back in 2010. On a prospective cohort study, Martin et al evaluated the outcomes of MWA on a variety of liver neoplasms of which the majority were CRLM. Furthermore, the matched comparison of 40 patients undergoing MWA and 40 patients undergoing RFA, MWA came advantageous in every outcome [37]. Since then, only four other studies [38-41] have compared the outcomes of these two ablation techniques (Table I). From our recently published experience we did not find any differences between MWA or RFA. However, incomplete ablation rate and the procedure time were both in favor of MWA [40].

We do have a completely different story for CRCLM with a diameter $>3 \mathrm{~cm}$ or for those in close proximity to vessels (fig 5). For these entities MWA might be more appropriate. The study of Ierardi et al that included 25 patients with unresectable hepatic metastases in whom RFA had limited applicability (lesions either greater than $3 \mathrm{~cm}$ or lesions in close proximity to major vessels) reported a $100 \%$ technical success rate for MWA [42].

For the time being, it is quite difficult to state that MWA is superior to RFA in terms of OS or complication rate, since no randomized control studies have been published. However, we do know for sure that MWA is faster and we can only speculate that MWA might be more appropriate for CRCLM $>3 \mathrm{~cm}$. For these reasons in our center we almost always (especially for lesions between or greater than 2-3 cm, or in case of multiple or bilobar lesions) prefer MWA instead of RFA for the treatment of CRCLM not suitable for surgery. Now, there are many ablation devices on the market but we should always keep in mind that surgery is the first line treatment for these patients.

\section{MWA in hepatocellular carcinoma}

MWA is an effective local thermal ablation technique for treating HCC that exhibits many advantages over other methods [43]. Despite the theoretical advantages of MWA over RFA the majority of the studies performed between 2002-2015 have found no significant differences between these two techniques [44-46]. However, it must be emphasized that the majority of the initial studies were retrospective in nature and on small cohorts. Until now, only 5 randomized control (RCT) studies were published showing no difference between MWA and RFA for small HCC [46-50] (Table II). Consequently, two metanalysis found no major differences between the two ablation techniques [51-52]. The only difference was in terms of the local recurrence rate (MWA outperformed RFA in cases of larger nodules) [51] and in terms of local tumor progression (reduced by 30\% with MWA versus RFA) [52]. After almost two decades it has now become clear that for lesions up to $3 \mathrm{~cm}$ there is no difference between MWA and RFA in terms of complete ablation rate, LTP, disease free survival, OS, or complications. However, in terms of costs and procedure time $(9.0 \pm 4.6$ minutes vs. $24.4 \pm 10.6$ minutes, $\mathrm{p}<0.001)$ one RCT showed MWA to be less expensive and faster than RFA [49].

A totally different scenario is the treatment of medium size HCC, which is defined as a lesion between 3 and $5 \mathrm{~cm}$ (fig 6). In a recent propensity score matching analysis that included 126 patients treated with MWA and 436 patients treated with RFA, MWA resulted in a better 5 -year overall survival $(79.3 \%$ vs $68.4 \%, \mathrm{p}=0.021)$ and a 5 -year recurrence-free survival $(27.9 \%$ vs $6.4 \%$, $\mathrm{p}<0.001)$ than RFA for HCC [53]. One other treatment modality for medium size $\mathrm{HCC}$ is transartherial chemoembolization (TACE). For medium size HCC, MWA provided significantly better OS and PFS than TACE for both the entire cohort (OS, $p<0.001$; PFS, $p<0.001$ ) and the matched cohort (OS, $\mathrm{p}=0.015$; PFS, $\mathrm{p}<0.001$ ) [54].

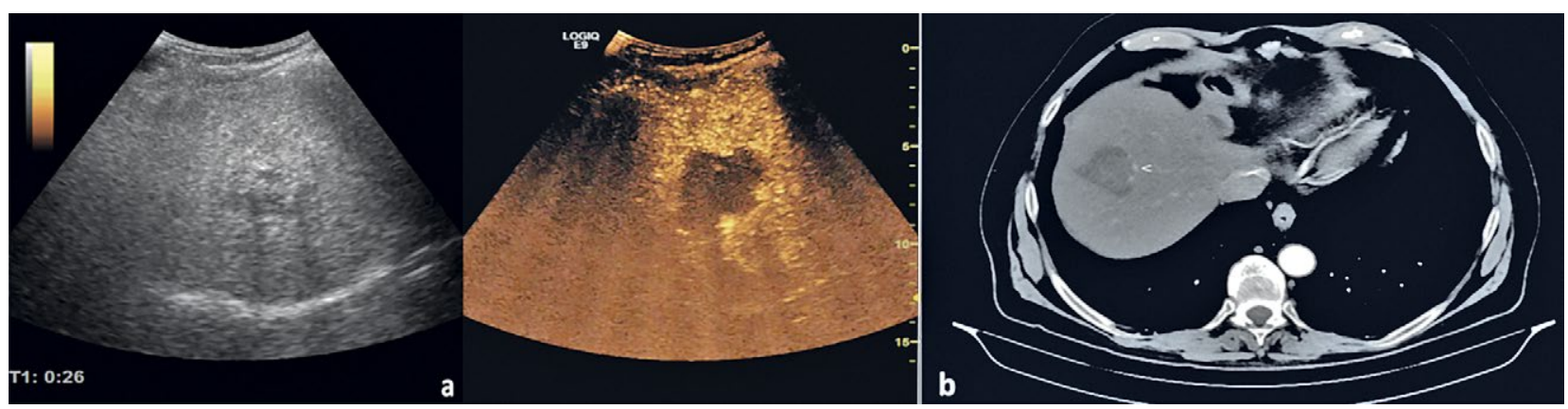

Fig 5. MWA of a $3 \mathrm{~cm}$ colorectal cancer metastasis: a) CEUS and b) CECT evaluation 1 month after ablation showed a necrotic area larger than the tumor $(46 / 37 \mathrm{~mm})$, with no remaining enhancing areas. $(>)$. Portal branch in the vicinity of the lesion unaffected by ablation. 

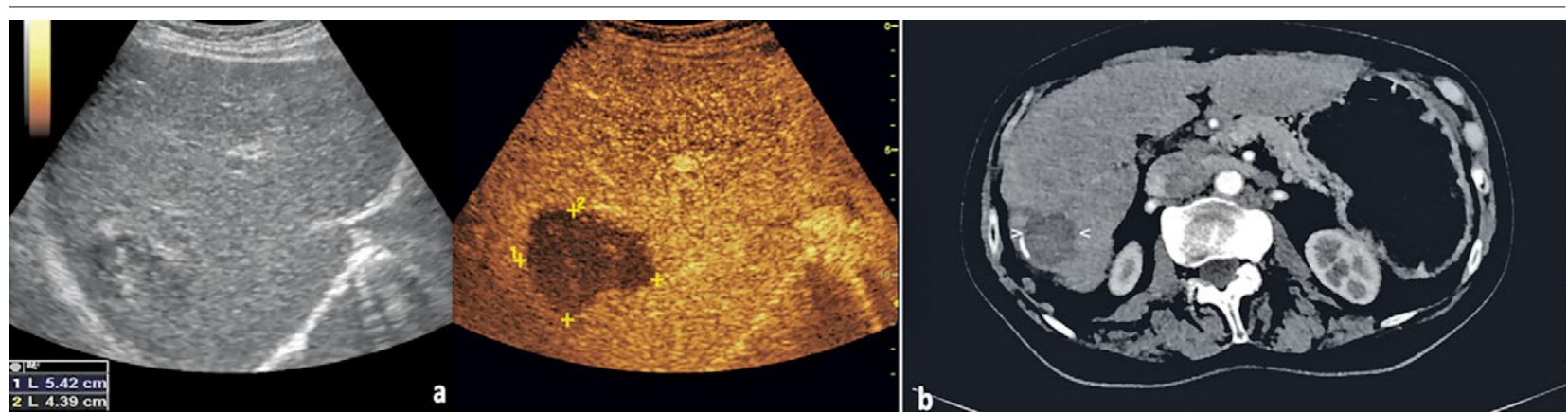

Fig 6. $4.0 \mathrm{~cm}$ hepatocellular carcinoma lesion in a cirrhotic liver. a) CEUS performed at the end of ablation showed a $49 / 46 \mathrm{~mm}$ necrotic area with no enhancement at the periphery; b) CT performed 3 months later confirmed that the tumor was completely ablated with no recurrence. The ablation area has shrunk to $39 / 36 \mathrm{~mm}$.

Another important clinical scenario is the intermediate size HCC, defined as a lesion greater than $5 \mathrm{~cm}$. For these entities MWA is less effective with complete ablation rates of $73-85 \%$, local recurrence rates of $19.2-$ $40.9 \%$ and $14.3-21.4 \%$ complications rates [55-57]. Overall survival rates are significantly lower than those encountered in medium size HCC $[55,56]$. Probably one of the most appealing research areas in the field of locoregional treatments for intermediate size HCC is the study of combined treatments. In respect to this, one meta-analysis included 9 studies that evaluated the efficacy of TACE combined with MWA versus TACE alone [58]. The pooled odds ratios for the 1-, 2-, and 3-year survival rates were in favor of TACE + MWA (OR $=3.29,95 \%$ CI 2.26-4.79; $\mathrm{OR}=2.82,95 \%$ CI $2.01-3.95 ; \mathrm{OR}=4.50$, 95\% CI 2.96-6.86; respectively) [58]. With all this in mind, future randomized control studies to confirm the superiority of combined MWA and TACE in comparison to TACE monotherapy are required.

Altogether, the treatment of small, medium and intermediate size $\mathrm{HCC}$ is not always straightforward. One should always keep in mind the facilities and local expe-

Table II. Randomized control clinical trials comparing MWA with RFA in patients with small HCC

\begin{tabular}{|c|c|c|c|c|c|c|}
\hline Author & $\begin{array}{l}\text { No of } \\
\text { patients }\end{array}$ & $\begin{array}{l}\text { Complete } \\
\text { ablation rate }\end{array}$ & $\begin{array}{l}\text { Local tumor } \\
\text { progression }\end{array}$ & $\begin{array}{l}\text { Disease free } \\
\text { survival }\end{array}$ & $\begin{array}{l}\text { Overall } \\
\text { survival }\end{array}$ & Complications \\
\hline $\begin{array}{l}\text { Shibata } \\
{[6]}\end{array}$ & 72 & $\begin{array}{l}96 \% \text { for RFA } \\
\text { and } \\
89 \% \text { for MWA, } \\
p=0.26\end{array}$ & $\begin{array}{l}4 \% \text { vs. } 10 \% \\
\text { at } 1 \text { year } \\
12 \% \text { vs. } 24 \% \\
\text { at } 2 \text { years } \\
\text { for RFA vs. MWA, } \\
p=0.20\end{array}$ & Not reported & Not reported & $\begin{array}{l}\text { No difference, } \\
p=0.67\end{array}$ \\
\hline $\begin{array}{l}\text { Chong } \\
{[47]}\end{array}$ & 93 & $\begin{array}{l}95.7 \% \text { for MWA } \\
\text { and } \\
97.8 \% \text { for } \mathrm{RFA} \text {, } \\
\mathrm{p}=0.99\end{array}$ & Not reported & $\begin{array}{l}51.1 \% \text { vs. } 57.7 \% \\
\text { at } 1 \text { year } \\
24.1 \% \text { vs. } 22.7 \% \\
\text { at } 3 \text { years } \\
\text { for MWA vs. RFA, } \\
p=0.91\end{array}$ & $\begin{array}{l}42.8 \% \text { vs. } 56.7 \% \\
\text { at } 1 \text { year } \\
\text { for MWA vs. RFA, } \\
p=0.89\end{array}$ & $\begin{array}{l}\text { No difference, } \\
p=0.99\end{array}$ \\
\hline $\begin{array}{l}\text { Kamal } \\
{[48]}\end{array}$ & 56 & Not reported & $\begin{array}{l}9.1 \% \text { vs. } 9.1 \% \\
\text { at } 1 \text { year } \\
\text { for MWA vs. RFA } \\
p=0.93\end{array}$ & Not reported & $\begin{array}{l}78.6 \% \text { vs. } 82.1 \% \\
\text { at } 1 \text { year } \\
\text { for MWA vs. RFA } \\
p=1.0\end{array}$ & $\begin{array}{l}\text { No difference, } \\
p=1.0\end{array}$ \\
\hline $\begin{array}{l}\mathrm{Yu} \\
{[49]}\end{array}$ & 203 & $\begin{array}{l}99.6 \% \text { for MWA } \\
\text { and } \\
98.8 \% \text { for } \mathrm{RFA} \text {, } \\
\mathrm{p}=0.95\end{array}$ & $\begin{array}{l}11.4 \% \text { vs. } 19.7 \% \\
\text { at } 5 \text { years } \\
\text { for MWA vs. RFA, } \\
p=0.11\end{array}$ & $\begin{array}{l}36.7 \% \text { vs. } 24.1 \% \\
\text { at } 5 \text { years } \\
\text { for MWA vs. RFA, } \\
p=0.07\end{array}$ & $\begin{array}{l}67.3 \% \text { vs. } 72.7 \% \\
\text { at } 5 \text { years } \\
\text { for MWA vs. RFA } \\
p=0.91\end{array}$ & $\begin{array}{l}\text { No difference, } \\
p=0.59\end{array}$ \\
\hline $\begin{array}{l}\text { Vietti Violi } \\
{[50]}\end{array}$ & 152 & $\begin{array}{l}5 \% \text { for MWA and } \\
4 \% \text { for RFA, } \\
p=0.94\end{array}$ & $\begin{array}{l}6 \% \text { vs. } 12 \% \\
\text { at } 2 \text { years } \\
\text { for MWA vs. RFA, } \\
p=0.27\end{array}$ & Nor reported & $\begin{array}{l}52 \% \text { vs. } 44 \% \\
\text { at } 2 \text { years } \\
\text { for MWA vs. RFA, } \\
p=0.18\end{array}$ & No difference \\
\hline
\end{tabular}

$\overline{\mathrm{MWA}}=$ microwave ablation; RFA = radiofrequency ablation; $\mathrm{No}=$ number; $\mathrm{p}=$ level of significance; $\mathrm{HCC}=$ hepatocellular carcinoma; $\mathrm{vs} .=\mathrm{versus}$ 


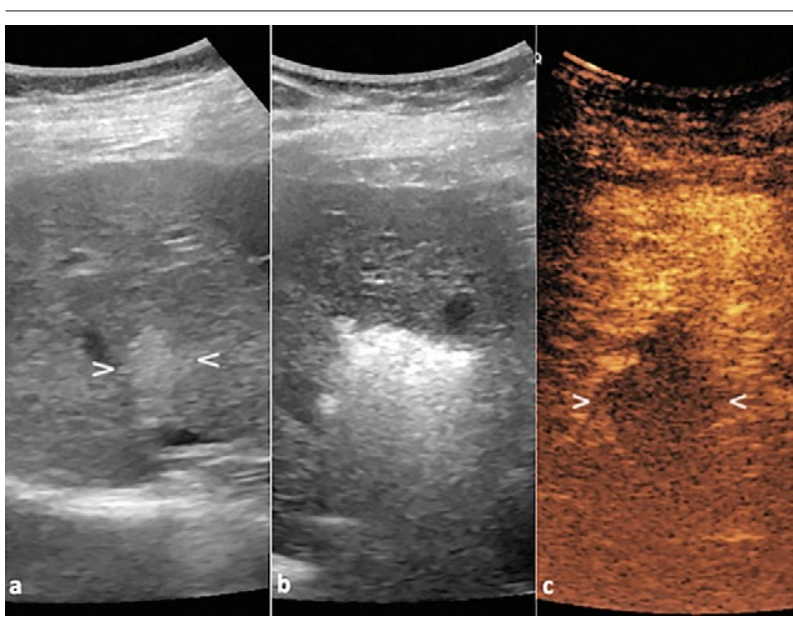

Fig 7. a) $1.8 \mathrm{~cm}$ hepatocellular carcinoma nodule close to a hepatic vein $(><)$. b) image during MWA; c) postprocedural CEUS confirmed the complete ablation of the lesion $(><)$

rience from each center. Our experience with percutaneous thermal ablation in HCC has been published a couple of years ago [59]. However, since then, we have changed our daily practice. For small HCC, if the nodule is less than $2 \mathrm{~cm}$ and solitary, we usually perform RFA. If the nodule is between $2-3 \mathrm{~cm}$ or in case of multiple nodules, we always prefer MWA, mainly because it is faster and in an overcrowded center, time is important. For medium size HCC we usually do MWA while TACE is reserved for those patients in whom percutaneous approach or ultrasound guidance is not possible. For intermediate size HCC patients, we first do TACE and then MWA if necessary.

\section{MWA in intrahepatic cholangiocarcinoma}

For a long time considered a rare clinical entity, the thermal ablation of iCCA has just recently been investigated by scientists. Therefore, the amount of evidence is rather limited at least when compared to HCC or CRCLM. The first study included 15 patients with iCCA. The ablation success rate, the technique effectiveness rate, and the local tumor progression rate were $91.7 \%$ $(22 / 24), 87.5 \%(21 / 24)$, and $25 \%(6 / 24)$ respectively. The cumulative overall $6,12,24$-month survival rates were $78.8 \%, 60.0 \%$, and $60.0 \%$, respectively [60]. Later on, another study that included 107 patients found out that Child-Pugh class A and less tumor number predict prolonged OS in patients with ICC treated by MWA [61], results which are similar to HCC patients. Nevertheless, MWA can also be used in patients with recurrent iCCA. In one retrospective study, the estimated 5-year OS rates were $23.7 \%$ after MWA and $21.8 \%$ after surgical resection (SR), while major complication rates in the SR group were higher than that in MWA ( $\mathrm{p}<0.001)$ (SR, $13.8 \%$ vs. MWA, 5.3\%) [62]. For the time being it is quite difficult to say which category of patients would benefit the most from MWA. It is certainly that surgery remains the first choice of therapy. Therefore, until further evidence and clinical practice guidelines, our best option is to use the criteria from HCC in iCCA as well.

\section{MWA in particularly located lesions}

Percutaneous ablation (RFA in particular) was shown to be less effective or associated with more complications in so-called "risky locations". More power (in case of MWA) equals less heat-sink effect but at the same time, more power might be more dangerous to the surrounding structure. Lesions located near large hepatic vessels (higher risk of partial necrosis or recurrences with RFA) can be treated effectively by MWA (fig 7) [63].

Lesions close to the diaphragm treated with MWA had a higher rate of recurrence and a higher complication rate compared to lesions away from the diaphragm $(5.5 \%$ vs. $0 \%$ ) but without statistical significance [64]. Lesions located near the gallbladder, hepatic hilum or adjacent to the gastrointestinal tract may be effectively and safely treated with MWA alone and/or in combination with ethanol injection. However, special precautions should be taken (less power setting) and additional techniques (e.g. strict temperature monitoring, artificially ascites or intrabiliary injection of cold saline) should be implemented to avoid damage of those structure [65-67].

\section{Conclusions}

MWA in liver cancer: is it a better tool or simply more power? In theory it is a better tool. However, in clinical practice more power is not always better. An evidence based answer for this intriguing question is quite challenging nowadays. However, some educated answers are warranted. For small HCC, MWA is simply more power and not a better tool since several RCT trials found no superiority over other ablative techniques. For CRCLM, there is, for sure, more power, but it is also possible to have a better tool at least when keeping in mind the existing literature, albeit retrospective. Medium and intermediate size nodules (HCC and metastasis) instead, is the place where more power becomes a better tool. Indeed, multi-centered, prospective and randomized controlled trials are still required in order to obtain evidence based answers for these challenging questions.

\section{Conflict of interest: none}

\section{References}

1. Van Cutsem E, Cervantes A, Adam R, et al. ESMO consensus guidelines for the management of patients with metastatic colorectal cancer. Ann Oncol 2016;27:1386-1422. 
2. European Association for the Study of the Liver. EASL Clinical Practice Guidelines: Management of hepatocellular carcinoma. J Hepatol 2018;69:182-236.

3. Vogl TJ, Nour-Eldin NA, Hammerstingl RM, Panahi B, Naguib NNN. Microwave ablation (MWA): Basics, technique and results in primary and metastatic liver neoplasms. Rofo 2017; 189:1055-1066.

4. Giorgio A, Gatti P, Matteucci P, Giorgio V. Ablative therapies for intrahepatic cholangiocarcinoma. Hepatobiliary Surg Nutr 2018;7:192-194.

5. Zhang K, Yu J, Yu X, et al. Clinical and survival outcomes of percutaneous microwave ablation for intrahepatic cholangiocarcinoma. Int J Hyperthermia 2018;34:292-297.

6. Meloni MF, Chiang J, Laeseke PF, et al. Microwave ablation in primary and secondary liver tumours: technical and clinical approaches. Int J Hyperthermia 2017;33:15-24.

7. Lubner MG, Brace CL, Hinshaw JL, Lee FT Jr. Microwave tumor ablation: mechanism of action, clinical results, and devices. J Vasc Interv Radiol 2010;21:S192-S203.

8. Hinshaw JL, Lubner MG, Ziemlewicz TJ, Lee FT Jr, Brace CL. Percutaneous tumor ablation tools: microwave, radiofrequency, or cryoablation--what should you use and why? Radiographics 2014;34:1344-1362.

9. Seror O. Ablative therapies: Advantages and disadvantages of radiofrequency, cryotherapy, microwave and electroporation methods, or how to choose the right method for an individual patient? Diagn Interv Imaging 2015;96:617-624.

10. Izzo F, Granata V, Grassi R, et al. Radiofrequency ablation and microwave ablation in liver tumors: an update. Oncologist 2019;24:e990-e1005.

11. Cazzato RL, De Marini P, Leclerc L, et al. Large nearly spherical ablation zones are achieved with simultaneous multi-antenna microwave ablation applied to treat liver tumours. Eur Radiol 2020;30:971-975.

12. Imajo K, Ogawa Y, Yoneda M, Saito S, Nakajima A. A review of conventional and newer generation microwave ablation systems for hepatocellular carcinoma. J Med U1trason (2001) 2020;47:265-277.

13. Imajo K, Tomeno W, Kanezaki M, et al. New microwave ablation system for unresectable liver tumors that forms large, spherical ablation zones. J Gastroenterol Hepatol 2018;33:2007-2014.

14. Yu H, Burke CT. Comparison of percutaneous ablation technologies in the treatment of malignant liver tumors. Semin Intervent Radiol 2014;31:129-137.

15. Liang P, Yu J, Lu MD, et al. Practice guidelines for ultrasound-guided percutaneous microwave ablation for hepatic malignancy. World J Gastroenterol 2013;19:5430-5438.

16. Wang T, Zhang XY, Lu X, Zhai B. Laparoscopic microwave ablation of hepatocellular carcinoma at liver surface: technique effectiveness and long-term outcomes. Technol Cancer Res Treat 2019;18:1533033818824338.

17. Yang B, Li Y. A comparative study of laparoscopic microwave ablation with laparoscopic radiofrequency ablation for colorectal liver metastasis. J BUON 2017;22:667-672.

18. Baker EH, Thompson K, McKillop IH, et al. Operative microwave ablation for hepatocellular carcinoma: a single center retrospective review of 219 patients. J Gastrointest Oncol 2017;8:337-346.

19. Sato M, Watanabe Y, Tokui K, Kawachi K, Sugata S, Ikezoe J. CT-guided treatment of ultrasonically invisible hepatocellular carcinoma. Am J Gastroenterol 2000;95:2102-2106.

20. Kurumi Y, Tani T, Naka S, et al. MR-guided microwave ablation for malignancies. Int J Clin Oncol 2007;12:85-93.

21. Liu F, Yu X, Liang P, Cheng Z, Han Z, Dong B. Contrastenhanced ultrasound-guided microwave ablation for hepatocellular carcinoma inconspicuous on conventional ultrasound. Int J Hyperthermia 2011;27:555-562.

22. Mauri G, Cova L, De Beni S, et al. Real-time US-CT/MRI image fusion for guidance of thermal ablation of liver tumors undetectable with US: results in 295 cases. Cardiovasc Intervent Radiol 2015;38:143-151.

23. Liu FY, Yu XL, Liang P, et al. Microwave ablation assisted by a real-time virtual navigation system for hepatocellular carcinoma undetectable by conventional ultrasonography. Eur J Radiol 2012;81:1455-1459.

24. Calandri M, Mauri G, Yevich S, et al. Fusion imaging and virtual navigation to guide percutaneous thermal ablation of hepatocellular carcinoma: A review of the literature. Cardiovasc Intervent Radiol 2019;42:639-647.

25. Patel PA, Ingram L, Wilson ID, Breen DJ. No-touch wedge ablation technique of microwave ablation for the treatment of subcapsular tumors in the liver. J Vasc Interv Radiol 2013;24:1257-1262.

26. Lekht I, Gulati M, Nayyar M, et al. Role of contrast-enhanced ultrasound (CEUS) in evaluation of thermal ablation zone. Abdom Radiol (NY) 2016;41:1511-1521.

27. Meloni MF, Andreano A, Franza E, Passamonti M, Lazzaroni S. Contrast enhanced ultrasound: Should it play a role in immediate evaluation of liver tumors following thermal ablation? Eur J Radiol 2012;81:e897-e902.

28. Sparchez Z, Radu P, Anton O, Socaciu M, Badea R. Contrast enhanced ultrasound in assessing therapeutic response in ablative treatments of hepatocellular carcinoma. J Gastrointestin Liver Dis 2009;18:243-248.

29. Wu JY, Chen MH, Yang W, et al. Role of contrast enhanced ultrasound in radiofrequency ablation of metastatic liver carcinoma. Chin J Cancer Res 2012;24:44-51.

30. Vogl TJ, Farshid P, Naguib NN, et al. Thermal ablation of liver metastases from colorectal cancer: radiofrequency, microwave and laser ablation therapies. Radiol Med 2014;119:451-461.

31. Bertot LC, Sato M, Tateishi R, Yoshida H, Koike K. Mortality and complication rates of percutaneous ablative techniques for the treatment of liver tumors: a systematic review. Eur Radiol 2011;21:2584-2596.

32. Liang P, Wang Y, Yu X, Dong B. Malignant liver tumors: Treatment with percutaneous microwave ablation-complications among cohort of 1136 patients. Radiology 2009;251:933-940.

33. Livraghi T, Meloni F, Solbiati L, Zanus G; Collaborative Italian Group using AMICA system. Complications of microwave ablation for liver tumors: results of a multicenter study. Cardiovasc Intervent Radiol 2012;35:868-874. 
34. Engstrand J, Nilsson H, Jansson A. A multiple microwave ablation strategy in patients with initially unresectable colorectal cancer liver metastases - A safety and feasibility study of a new concept. Eur J Surg Oncol 2014;40:1488-1493.

35. Manfredi S, Lepage C, Hatem C, et al. Epidemiology and management of liver metastases from colorectal cancer. Ann Surg 2006;244:254-259.

36. Dodd GD 3rd, Soulen MC, Kane RA, et al. Minimally invasive treatment of malignant hepatic tumors: at the threshold of a major breakthrough. Radiographics 2000;20:9-27.

37. Martin RC, Scoggins CR, McMasters KM. Safety and efficacy of microwave ablation of hepatic tumors: a prospective review of a 5-year experience. Ann Surg Oncol 2010;17:171-178.

38. Correa-Gallego C, Fong Y, Gonen M, et al. A retrospective comparison of microwave ablation vs. radiofrequency ablation for colorectal cancer hepatic metastases. Ann Surg Oncol 2014;21:4278-4283.

39. Shady W, Petre EN, Do KG, et al. Percutaneous microwave versus radiofrequency ablation of colorectal liver metastases: Ablation with clear margins (A0) provides the best local tumor control. J Vasc Interv Radiol 2018;29:268-275.

40. Sparchez Z, Mocan T, Hajjar NA, et al. Percutaneous ultrasound guided radiofrequency and microwave ablation in the treatment of hepatic metastases. A monocentric initial experience. Med Ultrason 2019;21:217-224.

41. Takahashi H, Kahramangil B, Kose E, Berber E. A comparison of microwave thermosphere versus radiofrequency thermal ablation in the treatment of colorectal liver metastases. HPB (Oxford) 2018;20:1157-1162.

42. Ierardi AM, Floridi C, Fontana F, et al. Microwave ablation of liver metastases to overcome the limitations of radiofrequency ablation. Radiol Med 2013;118:949-961.

43. Yu H, Burke CT. Comparison of percutaneous ablation technologies in the treatment of malignant liver tumors. Semin Intervent Radiol 2014;3:129-137.

44. Ding J, Jing X, Liu J, et al. Comparison of two different thermal techniques for the treatment of hepatocellular carcinoma. Eur J Radiol 2013;82:1379-1384.

45. Zhang L, Wang N, Shen Q, Cheng W, Qian GJ. Therapeutic efficacy of percutaneous radiofrequency ablation versus microwave ablation for hepatocellular carcinoma. PLoS One 2013;8:e76119.

46. Shibata T, Iimuro Y, Yamamoto Y, et al. Small hepatocellular carcinoma: comparison of radio-frequency ablation and percutaneous microwave coagulation therapy. Radiology 2002;223:331-337.

47. Chong CCN, Lee KF, Cheung SYS, et al. Prospective double-blinded randomized controlled trial of microwave versus radiofrequency ablation for hepatocellular carcinoma (McRFA trial). HPB (Oxford) 2020 Feb 8. doi:10.1016/j. hpb.2020.01.008.

48. Kamal A, Elmoety AAA, Rostom YAM, Shater MS, Lashen SA. Percutaneous radiofrequency versus microwave ablation for management of hepatocellular carcinoma: a randomized controlled trial. J Gastrointest Oncol 2019;10:562-571.
49. Yu J, Yu XL, Han ZY, et al. Percutaneous cooled-probe microwave versus radiofrequency ablation in early-stage hepatocellular carcinoma: a phase III randomised controlled trial. Gut 2017;66:1172-1173.

50. Vietti Violi N, Duran R, Guiu B, et al. Efficacy of microwave ablation versus radiofrequency ablation for the treatment of hepatocellular carcinoma in patients with chronic liver disease: a randomised controlled phase 2 trial. Lancet Gastroenterol Hepatol 2018;3:317-325.

51. Facciorusso A, Di Maso M, Muscatiello N. Microwave ablation versus radiofrequency ablation for the treatment of hepatocellular carcinoma: A systematic review and metaanalysis. Int J Hyperthermia 2016;32:339-344.

52. Glassberg MB, Ghosh S, Clymer JW, et al. Microwave ablation compared with radiofrequency ablation for treatment of hepatocellular carcinoma and liver metastases: a systematic review and meta-analysis. Onco Targets Ther 2019;12:6407-6438.

53. Liu W, Zheng Y, He W, et al. Microwave vs radiofrequency ablation for hepatocellular carcinoma within the Milan criteria: a propensity score analysis. Aliment Pharmacol Ther 2018;48:671-681.

54. Cui R, Wang XH, Ma C, et al. Comparison of microwave ablation and transarterial chemoembolization for singlenodule hepatocellular carcinoma smaller than $5 \mathrm{~cm}$ : A propensity score matching analysis. Cancer Manag Res 2019;11:10695-10704.

55. Liu Y, Zheng Y, Li S, Li B, Zhang Y, Yuan Y. Percutaneous microwave ablation of larger hepatocellular carcinoma. Clin Radiol 2013;68:21-26.

56. Liang PC, Lai HS, Shih TT, Wu CH, Huang KW. Initial institutional experience of uncooled single-antenna microwave ablation for large hepatocellular carcinoma. Clin Radiol 2015;70: e35-e40.

57. Medhat E, Abdel Aziz A, Nabeel M, et al. Value of microwave ablation in treatment of large lesions of hepatocellular carcinoma. J Dig Dis 2015;16:456-463.

58. Wang L, Ke Q, Lin N, Huang Q, Zeng Y, Liu J. The efficacy of transarterial chemoembolization combined with microwave ablation for unresectable hepatocellular carcinoma: a systematic review and meta-analysis. Int J Hyperthermia 2019;36:1288-1296.

59. Sparchez Z, Mocan T, Radu P, et al. Prognostic factors after percutaneous radiofrequency ablation in the treatment of hepatocellular carcinoma. Impact of incomplete ablation on recurrence and overall survival rates. J Gastrointestin Liver Dis 2018;27:399-407.

60. Yu MA, Liang P, Yu XL, et al. Sonography-guided percutaneous microwave ablation of intrahepatic primary cholangiocarcinoma. Eur J Radiol 2011;80:548-552.

61. Zhang K, Yu J, Yu X, et al. Clinical and survival outcomes of percutaneous microwave ablation for intrahepatic cholangiocarcinoma. Int J Hyperthermia 2018;34:292-297.

62. Xu C, Li L, Xu W, et al. Ultrasound-guided percutaneous microwave ablation versus surgical resection for recurrent intrahepatic cholangiocarcinoma: intermediate-term results. Int J Hyperthermia 2019;36:351-358. 
63. Huang S, Yu J, Liang P, Yu X, Cheng Z, Han Z, Li Q. Percutaneous microwave ablation for hepatocellular carcinoma adjacent to large vessels: a long-term follow-up. Eur J Radiol 2014;83:552-558.

64. Smolock AR, Lubner MG, Ziemlewicz TJ, et al. Microwave ablation of hepatic tumors abutting the diaphragm is safe and effective. AJR Am J Roentgenol 2015;204:197203.

65. Ren H, Liang P, Yu X, Wang Y, Lu T, Li X. Treatment of liver tumours adjacent to hepatic hilum with percutaneous microwave ablation combined with ethanol injection: a pilot study. Int J Hyperthermia 2011;27:249-254.

66. Huang H, Liang P, Yu XI, et al. Safety assessment and therapeutic efficacy of percutaneous microwave ablation therapy combined with percutaneous ethanol injection for hepatocellular carcinoma adjacent to the gallbladder. Int J Hyperthermia 2015;31:40-47.

67. Zhou P, Liang P, Yu X, Wang Y, Dong B. Percutaneous microwave ablation of liver cancer adjacent to the gastrointestinal tract. J Gastrointest Surg 2009;13:318-324. 